\title{
Paraparesia espástica complicada como fenótipo neurológico em OPA1
}

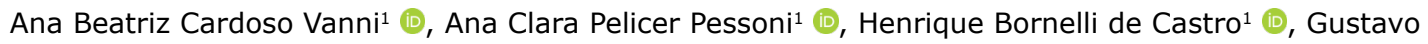
Novelino Simão ${ }^{1}$ (D), Zumira Aparecida Carneiro ${ }^{1}$ (D), Charles Marques Lourenço ${ }^{1}$ (D)

\begin{abstract}
RESUMO
Introdução: $A$ atrofia óptica autossômica dominante (ADOA) é uma das formas mais comuns de atrofias ópticas hereditárias, e causada por mutações no gene OPA1. Os pacientes afetados por essa doença geralmente apresentam perda visual na primeira década de vida, podendo apresentar manifestações extraoftalmológicas no decorrer dos anos, configurando uma síndrome chamada OPA1 plus ou ADOA-plus. Objetivos: Relatar caso de paciente portadora da síndrome ADOA-plus, estabelecendo correlações com casos descritos na literatura. Relato de caso: Paciente feminino, 30 anos, foi encaminhada para avaliação de quadro de atrofia óptica progressiva associada a sintomas de neuropatia periférica. Aos dois anos, foi diagnosticada com perda visual parcial em consulta de puericultura. Não relatou outros sintomas associados durante a infância e a adolescência. Aos 20 anos, apresentou dificuldades de deambular, fraqueza em membros inferiores e falta de equilíbrio. Aos 25 anos, após extensa investigação, foi identificada, através de sequenciamento de exoma, mutação patológica no gene OPA1 confirmando o diagnóstico ADOA-plus e iniciado tratamento com Coenzima Q10. Atualmente a paciente relata ataxia sensitiva, diminuição da acuidade visual progressiva, fasciculações e câimbras em MMII, disfagia e dispneia. Discussão: Muitos pacientes com ADOA-plus apresentam surdez neurossensorial como sintoma extraoftalmológico mais comum, além de quadros de parkinsonismo e demência, ataxia e ptose. Paciente relatada constitui um caso de atrofia óptica associado à neuropatia periférica, ataxia e miopatia. Devido à ampla variabilidade clínica dessa doença, deve-se investigar mutações no OPA1 em casos de paraparesia espástica progressiva associada à atrofia óptica, visto que possibilidade de tratamento com Coenzima Q10.
\end{abstract}

Palavras-chave: Atrofias ópticas hereditárias, Doenças do nervo óptico, Ataxia, Coenzima Q10.

1. Faculdade de Medicina. Centro Universitário Estácio de Ribeirão Preto, Ribeirão Preto, (SP), Brasil 


\section{INTRODUÇÃO}

As neuropatias ópticas mitocondriais são divididas em adquiridas e hereditárias; as hereditárias formam um grupo heterogêneo de doenças que se caraterizam por perda visual central bilateral simétrica moderada a grave, discromatopsia e palidez do disco óptico ${ }^{1}$. A atrofia óptica pode se caracterizar como um evento isolado ou fazer parte de um quadro sistêmico. As formas mais comuns de atrofias ópticas hereditárias são: a neuropatia óptica hereditária de Leber (LHON) e a atrofia óptica autossômica dominante (ADOA). ${ }^{5} \mathrm{~A}$ atrofia óptica do tipo 1 (OMIM \#165500), causada por mutações no gene $O P A 1$, é a doença responsável pela maior parcela dos casos de ADOA. ${ }^{2}$

Mais de 200 mutações patológicas no gene OPA1 foram identificadas e novas mutações continuam sendo descritas. ${ }^{3} \mathrm{O}$ gene OPA1 humano é um gene nuclear composto de 30 éxons no cromossomo 3q28-q294. A proteína produzida pelo gene é uma GTPase necessária para fusão da membrana interna das mitocôndrias e manutenção da arquitetura mitocondrial (Figura 1). A perda da função dessa proteína, portanto, leva à fragmentação mitocondrial e, eventualmente, à apoptose das células ganglionares da retina. ${ }^{8}$

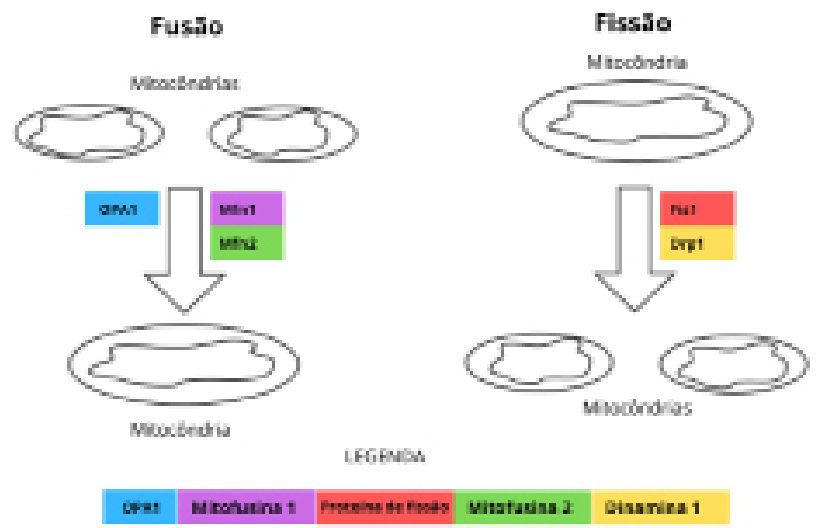

Figura 1. Dinâmica da fusão da membrana interna mitocondrial realizada pelas proteínas de fusão OPA1, Mitofusina 1 (Mfn1) e Mitofusina 2 (Mfn2) e fissão da mesma, realizada pela proteína de fissão (Fis1) e pela Dinamina 1 (Drp1).

Fonte: Os Autores (2020).

Nos pacientes portadores de mutação no gene OPA1, a manifestação clínica mais evidente, a perda visual, é observada ainda na primeira década de vida. ${ }^{6}$ No entanto, uma pequena parcela desses pacientes apresenta, posteriormente, manifestações extraoftalmológicas como perda auditiva, ataxia e miopatia. ${ }^{7}$

As manifestações extraoftalmológicas, quando ocorrem em pacientes com mutação no gene OPA1, configuram uma síndrome, chamada OPA1 plus, ou ADOA + (OMIM \#125250) $)^{3,4}$. A idade em que se estabelece a perda visual não varia entre a ADOA e a $A D O A+$, entretanto os pacientes com as manifestações extraoftalmológicas apresentam perdas visuais de maior gravidade. ${ }^{3}$ Os demais sintomas aparecem pelo menos uma década ou mais após o primeiro, podendo se instalar até a quarta década de vida. ${ }^{3}$

O presente estudo visa relatar o caso de uma paciente portadora de síndrome de ADOA+, diagnosticada com perda visual na infância e sintomas extraoftalmológicos na vida adulta, para elucidar o fenótipo da doença e estabelecer correlações com os casos descritos na literatura.

\section{RELATO DE CASO}

Paciente do sexo feminino, 30 anos, filha de pais não consanguíneos, foi encaminhada para avaliação de quadro de atrofia óptica progressiva associada a sintomas de neuropatia periférica.

Seus antecedentes gestacionais e neonatais não revelaram intercorrência. Durante a gestação, não houve exposição a agentes teratogênicos, nasceu a termo, teve alta no segundo dia de vida, sendo essas as únicas informações relatadas pela paciente nesse período.

A partir dos dois anos apresentou quadro de perda visual parcial, que em puericultura foi avaliada como perda visual parcial de caráter progressivo associada a estrabismo divergente. Durante a infância e adolescência, paciente não relatou problemas de saúde.

Aos 20 anos apresentou dificuldade de deambular sem apoio em linha reta, fraqueza em membros inferiores, desequilíbrio para levantar, agachar e correr. A partir de então, iniciou acompanhamento neurológico em que foram solicitados exames como punção lombar, inalterado, e exames de sangue (Tabela 1).

Antecedentes familiares não revelaram casos semelhantes na família de atrofia óptica ou doença neurológica progressiva. Genitora da paciente possui histórico de "paralisia infantil" (sic).

Aos 25 anos, foi encaminhada ao serviço terciário para acompanhamento neurogenético, onde 
foi realizada biópsia muscular, que evidenciou discreta irregularidade do diâmetro das miofibras, raras fibras hipotróficas, sem fluxo de células inflamatórias. A eletroneuromiografia foi compatível com uma neuropatia sensitivo-motora axonal, sendo o componente motor comprimento-dependente, com sinais de atividade.

Tabela 1. Exames laboratoriais

\begin{tabular}{lcc}
\hline & Valor & $\begin{array}{c}\text { Valor de } \\
\text { Referência }\end{array}$ \\
\hline $\begin{array}{l}\text { Lactato } \\
\text { (repouso) }\end{array}$ & $1,3 \mathrm{mmol} / \mathrm{L}$ & $0,5-2 \mathrm{mmol} / \mathrm{L}$ \\
$\begin{array}{l}\text { Lactato } \\
\text { (esforço) }\end{array}$ & $5,8 \mathrm{mmol} / \mathrm{L}$ & $0,5-2 \mathrm{mmol} / \mathrm{L}$ \\
Cálcio iônico & $1,2 \mathrm{mmol} / \mathrm{L}$ & $1,12-1,32 \mathrm{mmol} / \mathrm{L}$ \\
Sódio & $139 \mathrm{mmol} / \mathrm{L}$ & $135-145 \mathrm{mmol} / \mathrm{L}$ \\
Potássio & $4 \mathrm{mmol} / \mathrm{L}$ & $3,5-5 \mathrm{mmol} / \mathrm{L}$ \\
CPK & $198 \mathrm{U} / \mathrm{L}$ & $24-170 \mathrm{U} / \mathrm{L}$ \\
TGO & $22 \mathrm{U} / \mathrm{L}$ & $<32 \mathrm{U} / \mathrm{L}$ \\
TGP & $15 \mathrm{U} / \mathrm{L}$ & $<31 \mathrm{U} / \mathrm{L}$ \\
Ácido úrico & $4,4 \mathrm{mg} / \mathrm{DL}$ & $2-5 \mathrm{mg} / \mathrm{DL}$ \\
Glicemia & $79 \mathrm{mg} / \mathrm{DL}$ & $70-100 \mathrm{mg} / \mathrm{DL}$ \\
Vitamina B12 & $252 \mathrm{pg} / \mathrm{mL}$ & $174-878 \mathrm{pg} / \mathrm{mL}$ \\
Magnésio & $1,58 \mathrm{mEq} / \mathrm{L}$ & $1,4-2,3 \mathrm{mEq} / \mathrm{L}$ \\
\hline
\end{tabular}

Fonte: Os autores (2020).

Após extensa avaliação clínica e laboratorial sem elucidação do quadro da paciente, optouse pela realização de exame de sequenciamento completo de exoma, o qual revelou presença, em heterozigose, da variante missense c.1311A > G;p (Ile437Met), classificada como patogênica no gene OPA1, confirmando o diagnóstico de Atrofia Óptica do tipo 1 plus (ADOA plus). Após o diagnóstico, foi realizado exame de Ressonância Magnética (Figura 2), cujos achados justificam a clínica da paciente.

Atualmente, paciente relata ataxia sensitiva, diminuição da acuidade visual progressiva, fasciculações e câimbras em MMII, disfagia, dispneia aos pequenos esforços e mal-estar se jejum prolongado. Ao exame físico, paciente encontra-se orientada no tempo e espaço; fácies simétrico, presença de estrabismo divergente, eleva palato simetricamente, língua centrada; eumetria e eudiadococinesia; reflexos osteotendíneos grau 2 em MMII e grau 3 em MMSS; força muscular grau 4 em MMII e MMSS (exceto, MIE grau 4-); hipertonia de flexores plantares, Mingazini MMII postivo, arco plantar aumentado bilateral, dedos em flexão, fraqueza de isquiotibial, alteração de sensibilidade vibratória de MMII; marcha atípica - necessita de uso de apoio de bengala para caminhar.

Como tratamento farmacológico faz uso de coenzima $\mathrm{Q}_{10} 450 \mathrm{mg}$, três vezes ao dia e, como terapia de reabilitação, realiza aulas de pilates semanalmente. Avaliação com equipe de fisioterapia indicou necessidade de uso de órteses em pés.

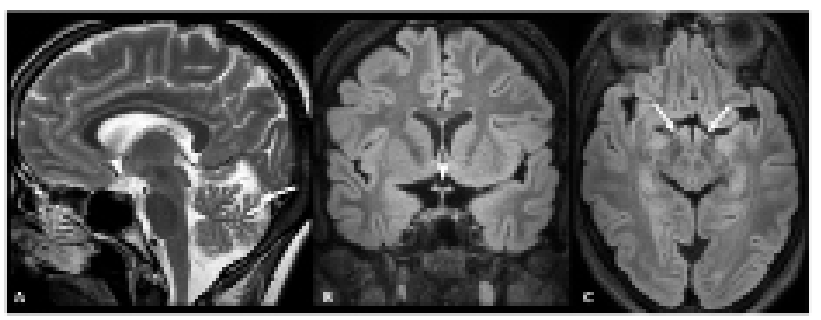

Figura 2. Imagens em ressonância magnética da paciente, 27 anos, com OPA1. A: Sagital T2 demonstrando a atrofia cerebelar (seta) e do nervo/quiasma óptico (ponta de seta). B e C: Coronal e axial T2 FLAIR evidenciando discreto hipersinal e atrofia do quiasma (ponta de seta) e dos tratos ópticos (setas).

Fonte: Os autores (2020).

\section{DISCUSSÃO}

Apesar da expressividade ser bastante variável, a maioria dos casos de ADOA na infância ou adolescência apresenta majoritariamente atrofia óptica progressiva isolada. ${ }^{12}$ Os pacientes que desenvolvem manifestações extraoculares representam $20 \%$ dos casos e são então denominados ADOA+ ${ }^{9}$. Essas formas sindrômicas de atrofia óptica causadas por variantes no sequenciamento do OPA1, foram descritas com surdez neurosensorial como o achado mais comum ${ }^{12}$, em aproximadamente dois em cada três pacientes ${ }^{10}$. Entretanto, apesar de a paciente em questão apresentar o acometimento visual como primeiro sintoma na infância, até o momento, não evidenciou sinais de surdez neurossensorial.

Ainda, a ADOA+ pode ser associada, mais raramente, com várias combinações de sintomas incluindo ptose, oftalmoplegia externa progressiva crônica, polineuropatia periférica, ataxia, paraparesia espástica, esclerose múltipla-like e miopatia. ${ }^{10}$ Já no caso apresentado, a paciente, até então, não possui ptose ou oftalmoplegia, sendo um caso de atrofia óptica associado à neuropatia periférica, ataxia e miopatia.

Embora não tenha sido observada na paciente até o momento, a associação entre oftalmoplegia 
externa progressiva crônica e parkinsonismo/demência com neuropatia óptica subclínica, amplia o espectro fenotípico das mutações do OPA1, evidenciando a associação entre defeitos mitocondriais, múltiplas deleções do mtDNA e remoção seletiva de mitocôndrias (mitofagia) com parkinsonismo. ${ }^{13}$

O fenótipo da ADOA+, similar ao observado em desordens mitocondriais multissistêmicas, é frequentemente associado com mutações missense no $O P A 1^{14}$, variante encontrada na paciente relatada. Além dessas formas autossômicas dominantes, apenas alguns casos sindrômicos foram descritos com mutações heterozigóticas compostas no OPA1, sugestivas de padrões de herança recessiva ou semidominante. ${ }^{9}$ Recentemente, mutações recessivas no OPA1 vêm sendo descritas, cujo fenótipo tende a ser mais grave do que o observado nas formas dominantes do OPA1, podendo haver associação com catarata, além da atrofia óptica. Até o momento, sete pacientes, de quatro famílias não aparentadas foram descritos com duas mutações diferentes no OPA1. Entretanto, a heterozigose composta do OPA1 foi encontrada em apenas três pacientes de duas famílias sem parentesco. ${ }^{14}$

Como as formas de OPA1 estão mais associadas com herança dominante, 0 aconselhamento genético de famílias afetadas por essa enfermidade é fundamental, visto que o risco de recorrência chega a $50 \%$ em futura prole desses casais. É importante ressaltar, porém, que há heterogeneidade fenotípica intrafamiliar, ou seja, a mesma mutação no OPA1 em uma família não necessariamente evolui com o mesmo quadro clínico (ou com a mesma gravidade) em todos os afetados. ${ }^{10}$

Apenas alguns casos de ADOA+ foram relacionados com o domínio básico do OPA1 e nenhum deles tiveram espasticidade. Ademais, evidências clínicas de acometimento do trato corticoespinhal são incomuns nas doenças relacionadas com o OPA $1^{11}$. Curiosamente, a paciente em questão apresenta quadro progressivo de paraparesia espástica, um fenótipo clínico não tão frequente em pacientes com mutação no OPA1.

Os achados de neuroimagem encontrados em pacientes com mutações no OPA1 consistem em atrofia cerebral e cerebelar, afilamento dos nervos ópticos e anormalidades no sinal da substância branca, condizentes com os achados encontrados na neuroimagem da paciente relatada (Figura 2). Além desses achados, já foram descritos sinais neurorradiológicos típicos de síndrome de Leigh/
Leigh-like em pacientes com OPA1. Recentemente, sinais de AVC metabólico muito similares aos já descritos na síndrome de MELAS têm sido relatados em alguns pacientes portadores de mutação OPA1. No entanto, ainda é muito precoce dizer se investigação do OPA1 deve ser feita em pacientes com suspeita de AVC metabólico. ${ }^{15}$

Quanto ao tratamento, sabe-se que não há nenhuma terapia específica aprovada até então. No entanto, os pacientes parecem se beneficiar com antioxidantes, como a coenzima $\mathrm{Q}_{10}$ que já é utilizada no tratamento de outras doenças mitocondriais, como a Neuropatia Óptica Hereditária de Leber (LHON). ${ }^{16}$ Especificamente, a Idebenona, forma sintética da coenzima $\mathrm{Q}_{10}$, tem apresentado resultados satisfatórios na estabilização e na melhora da acuidade visual dos pacientes com ADOA $^{17,18}$ por ser um cofator essencial da produção de ATP nas mitocôndrias, cuja dinâmica de funcionamento está prejudicada nessa doença. ${ }^{19}$

Em suma, mutações do OPA1 estão geralmente relacionadas a quadros de atrofia óptica com ou sem surdez neurossensorial. No entanto, mais e mais evidências apontam para formas multissistêmicas da doença, que podem se apresentar de variadas maneiras, inclusive com neuropatia periférica. No caso da nossa paciente, a combinação de paraparesia espástica com neuropatia periférica não iria tradicionalmente fazernos pensar em mutações no OPA1, mas sim em outras formas genéticas de paraparesia espástica. Dessa maneira, reforçamos que, na investigação da paraparesia progressiva associada à neuropatia periférica e, particularmente, à atrofia óptica, é fundamental excluir a possibilidade de um quadro provocado por mutações no OPA1, visto que há a possibilidade terapêutica com o uso da Idebenona/Coenzima $\mathrm{Q}_{10}$.

\section{REFERÊNCIAS}

1. Pilz YL, Bass SJ, Sherman J. A Review of Mitochondrial Optic Neuropathies: From Inherited to Acquired Forms. J Optom. 2017;10(4):205-14.

2. Cohen L, Tzur S, Goldenberg-Cohen N, Bormans C, Behar $D M$, Reinstein E. Exome sequencing identified a novel de novo OPA1 mutation in a consanguineous family presenting with optic atrophy. Genetics Research. 2016;98:e10.

3. Skidd PM, Lessell S, Cestari DM. Autosomal Dominant Hereditary Optic Neuropathy (ADOA): A Review of the Genetics and Clinical Manifestations of ADOA and ADOA+. Seminars in Ophthalmology. 10 de setembro de $2013 ; 28(5-6): 422-6$. 
4. Chun BY, Rizzo JFI. Dominant optic atrophy: updates on the pathophysiology and clinical manifestations of the optic atrophy 1 mutation. Current Opinion in Ophthalmology. novembro de 2016;27(6):475.

5. Yu-Wai-Man $P$, Votruba $M$, Burté $F$, La Morgia $C$, Barboni $P$, Carelli V. A neurodegenerative perspective on mitochondrial optic neuropathies. Acta Neuropathol. 2016;132(6):789-806.

6. Nasca A, Rizza T, Doimo M, Legati A, Ciolfi A, Diodato D, et al. Not only dominant, not only optic atrophy: expanding the clinical spectrum associated with OPA1 mutations. Orphanet journal of rare diseases. 2017;12(1):89.

7. Amati-Bonneau $P$, Milea $D$, Bonneau $D$, Chevrollier $A$, Ferré $M$, Guillet V, et al. OPA1-associated disorders: phenotypes and pathophysiology. The international journal of biochemistry \& cell biology. 2009;41(10):1855-1865.

8. Carelli V, La Morgia C, Ross-Cisneros FN, Sadun AA. Optic neuropathies: the tip of the neurodegeneration iceberg. Human molecular genetics. 2017;26(R2):R139-R150.

9. Lee J, Jung S-C, Hong YB, Yoo JH, Koo H, Lee JH, et al. Recessive optic atrophy, sensorimotor neuropathy and cataract associated with novel compound heterozygous mutations in OPA1. Molecular Medicine Reports. 10 de julho de $2016 ; 14(1): 33-40$.

10. Yu Wai Man P, Griffiths PG, Gorman GS, Lourenco CM, Wright AF, Auer-Grumbach M, et al. Multi-system neurological disease is common in patients with OPA1 mutations. Brain : a journal of neurology. 2010;133(3): 771-786

11. Kazamel M, Wong L-J, Milone M. Novel OPA1 mutation featuring spastic paraparesis and intestinal dysmotility. Mol Genet Metab Rep. 8 de outubro de 2014;1:443-5.
12. Liskova $\mathrm{P}$, Ulmanova $\mathrm{O}$, Tesina $\mathrm{P}$, Melsova $\mathrm{H}$, Diblik $\mathrm{P}$, Hansikova $\mathrm{H}$, et al. Novel OPA1 missense mutation in a family with optic atrophy and severe widespread neurological disorder. Acta Ophthalmol. maio de 2013;91(3):e225-231.

13. Carelli V, Musumeci O, Caporali L, Zanna C, Morgia CL, Dotto VD, et al. Syndromic parkinsonism and dementia associated with OPA1 missense mutations. Annals of Neurology. 2015;78(1):21-38.

14. Bonneau $D$, Colin $E$, Oca F, Ferré $M$, Chevrollier $A$, Guéguen $N$, et al. Early-onset Behr syndrome due to compound heterozygous mutations in OPA1. Brain. 10 de outubro de 2014;137(10):e301-e301.

15. Zerem A, Yosovich K, Rappaport Y, Libzon S, Blumkin L, Liat $\mathrm{B}-\mathrm{S}$, et al. Metabolic stroke in a patient with bi-allelic OPA1 mutations. Metabolic Brain Disease. 10 de abril de 2019;34.

16. Newman NJ. Treatment of Leber hereditary optic neuropathy. Brain. setembro de 2011;134(9):2447-50.

17. Romagnoli M, Morgia CL, Carbonelli M, Vito LD, Amore $G$, Zenesini $C$, et al. Idebenone increases chance of stabilization/recovery of visual acuity in OPA1-dominant optic atrophy. Annals of Clinical and Translational Neurology. 2020;7(4):590-4.

18. Barboni $\mathrm{P}$, Valentino $\mathrm{ML}$, La Morgia C, Carbonelli M, Savini G, De Negri $A$, et al. Idebenone treatment in patients with OPA1-mutant dominant optic atrophy. Brain. fevereiro de 2013;136(Pt 2):e231.

19. Takahashi K, Ohsawa I, Shirasawa T, Takahashi M. Optic atrophy 1 mediates coenzyme Q-responsive regulation of respiratory complex IV activity in brain mitochondria. Experimental Gerontology. 10 de novembro de 2017;98:217-23. 


\section{Autor Correspondente:}

Charles Marques Lourenço

charlesgenetica@gmail.com

Editor:

Prof. Dr. Felipe Villela Gomes

Recebido: 08/03/2021

Aprovado; 14/04/2021 